\title{
Renal tubular dysgenesis
}

INSERM

\section{Source}

INSERM. (1999). Orphanet: an online rare disease and orphan drug data base. Renal tubular dysgenesis. ORPHA:3033

Renal tubular dysgenesis is a rare disorder of the fetus characterized by absent or poorly developed proximal tubules of the kidneys, persistent oligohydramnios, leading to Potter sequence (facial dysmorphism with large and flat low-set ears, lung hypoplasia arthrogryposis and limb positioning defects), and skull ossification defects. It can be acquired during fetal development due to drugs taken by the mother or certain disorders (twin-twin transfusion syndrome, TTTS; see this term) or inherited in an autosomal recessive manner. 